\title{
Molten Salt Reactors
}

\author{
(C) Thomas J. Dolan, Member, IEEE 2021
}

\begin{abstract}
Nuclear power is advancing slowly because of public concerns about nuclear accidents, radioactive waste, fuel supply, cost, and nuclear proliferation. The development of molten salt reactors could alleviate most of these concerns and prevent water-cooled reactor accidents like those at Three Mile Island, Chernobyl, and Fukushima. The purpose of this article is to provide information about the potential advantages and problems of molten salt reactors. The coolants could be either fluorides or chlorides, operated above their melting temperatures, to avoid solidification, and well below their boiling temperatures, to prevent evaporation losses. "Fast" reactors use energetic fission neutrons, while "thermal" reactors use graphite to slow the neutrons down to thermal energies. We describe four reactor types: solid fuel thermal, liquid fuel thermal, liquid fuel fast, and "stable salt" fast reactors (liquid fuel in tubes). We discuss load following, reactor design projects, and development problems. Liquid fuel reactors will require a chemical processing plant to adjust fissile fuel inventory, fission products, actinides, and corrosivity in a hot, highly-radioactive environment.
\end{abstract}

Index Terms - molten salt, safety, electricity generation, low pressure, thermal reactor, fast reactor, liquid fuel, breeder, energy.

\section{INTRODUCTION}

Oak Ridge National Laboratory (ORNL) built the 8 MWth Molten Salt Reactor Experiment (MSRE, 1965-1969), which used liquid fuel of "Flibe" $\left({ }^{7} \mathrm{LiF}-\mathrm{BeF}_{2}\right)$ containing $\mathrm{ZrF}_{4}$ and $U_{\mathrm{X}}$ salts, Fig. 1.

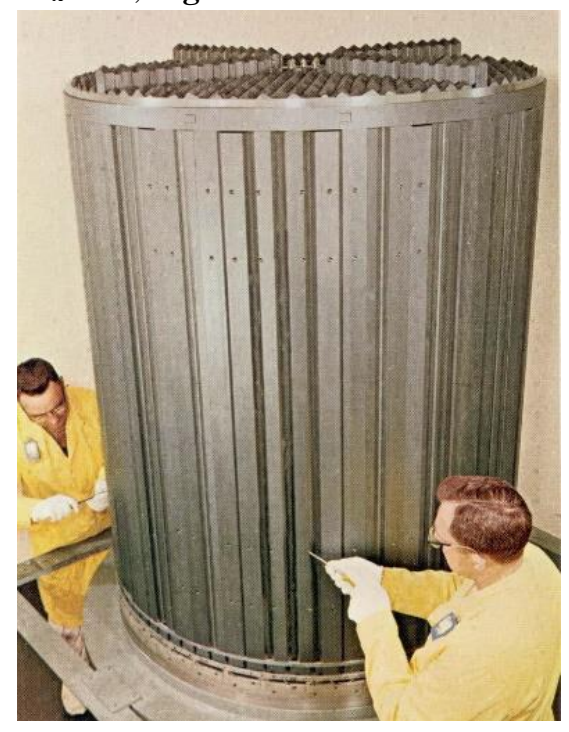

Submitted for review 2021.04.25 Thomas J. Dolan is in the Department of Nuclear, Plasma, and Radiological Engineering, University of Illinois at Urbana-Champaign, IL 61801 USA. (email: dolantj@illinois.edu ) .
Fig. 1. MSRE core. Liquid fuel flowed upwards through channels in the graphite. [ORNL]

The MSRE demonstrated that the issues of control, pumping, heat removal, radioactivity containment, and corrosion could be managed. Oak Ridge also designed a Molten Salt Breeder Reactor (MSBR) that would produce more fuel than it burned, using Flibe salt with dissolved $\mathrm{ThF}_{4}$ and ${ }^{233} \mathrm{UF}_{4}$. It would have had a breeding ratio (BR) of 1.06 and a fuel doubling time of 22 years, but funding was MSRs

Neutrons emitted by fission start at high energies, called "fast neutrons". With a graphite "moderator" the neutrons bounce around and slow down to low energies, called "thermal neutrons". Reactors using mainly fast neutrons or thermal neutrons are called fast reactors or thermal reactors.

Reactors with solid fuels, such as rods or ceramic pebbles, could operate safely at high temperature and low pressure. The high temperature increases electrical power generation efficiency and enables use of gas turbines for electricity generation. The low-pressure vessels would be safer and less expensive than current high-pressure vessels required for water coolants.

Solid fuel MSRs could have the following advantages in comparison with present water-cooled reactors:

- Water-free core $\rightarrow$ no evaporation, steam pressure, or hydrogen generation. (The accidents at Three Mile Island, Chernobyl, and Fukushima would not have occurred.)

- Higher temperature coolant $\rightarrow$ efficiency of electricity generation

- Low pressure coolant $\rightarrow$ less danger of failure; less expensive vessel and plumbing

Liquid fuels, such uranium tetrafluoride $\left(\mathrm{UF}_{4}\right)$ dissolved in the coolant salt, could be processed onsite to adjust reactivity and remove some fission products, extending core life for decades. Either the $\mathrm{U}^{2}{ }^{239} \mathrm{Pu}$ fuel cycle or the $\mathrm{Th}^{-233} \mathrm{U}$ fuel cycle could breed additional fissile fuel, reducing the need for ${ }^{235} \mathrm{U}$ enrichment. MSRs could also burn actinides $(\mathrm{Z} \geq 89)$ from used LWR fuel, reducing the need for high-level waste disposal in repositories like Yucca Mountain. Liquid fuels would have no solid fuel element manufacture, clad damage danger, or refueling shutdown to deal with. On-line processing 
could adjust fissile composition, remove some fission products to improve neutron economy, and recycle actinides. If the core overheated, drain plugs would melt, allowing the fuel salt to flow down into passively cooled drain tanks. Capital and fuel costs could be lower than those of LWRs and coal power plants. ${ }^{\mathrm{i}}$

Fig. 2 shows a simplified liquid fuel MSR.

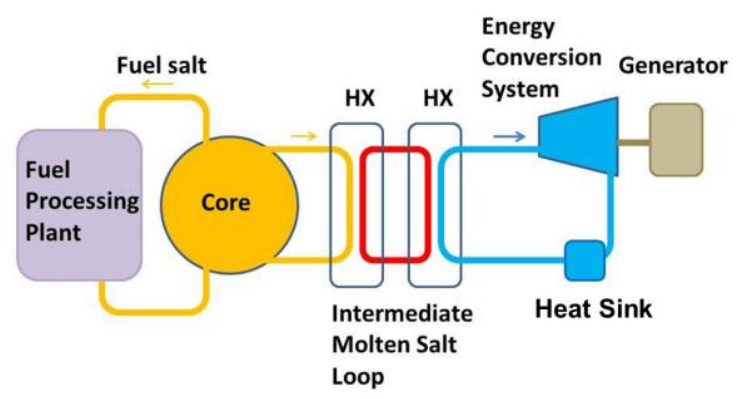

Fig. 2. Simplified view of a liquid fuel MSR power plant.

The fuel salt contains fissile material dissolved in coolant salt, such as Flibe. It flows to a heat exchanger HX, where intermediate coolant salt carries the heat to the Rankine or Brayton energy conversion system that generates electricity. The intermediate coolant loop isolates the energy conversion system from the core radioactivity (fission products, actinides, and tritium). Drain tanks and pumps are not shown.

If the reactor has a breeding ratio $>1.0$ the extra neutrons emitted could breed fissile ${ }^{233} \mathrm{U}$ from ${ }^{232} \mathrm{Th}$ and fissile ${ }^{239} \mathrm{Pu}$ from ${ }^{238} \mathrm{U}$. The transition to a breeder fuel cycle could extract much more of the nuclear energy potentially available from $U$ and Th, sustaining nuclear power for centuries. Thorium is an inexpensive byproduct of rare earths, iron, titanium, and phosphate mining. About 80,000 tonnes of thorium could be recovered from mines producing 7 million tons of titanium per year, which would greatly exceed the need of a worldwide thorium breeder reactor fleet.

\section{SOLID FUEL THERMAL REACTOR}

One example solid fuel design is the fluoride-cooled high-temperature reactor (FHR), which is like a high temperature gas cooled reactor (HTGR) with the gas coolant replaced by molten salt.

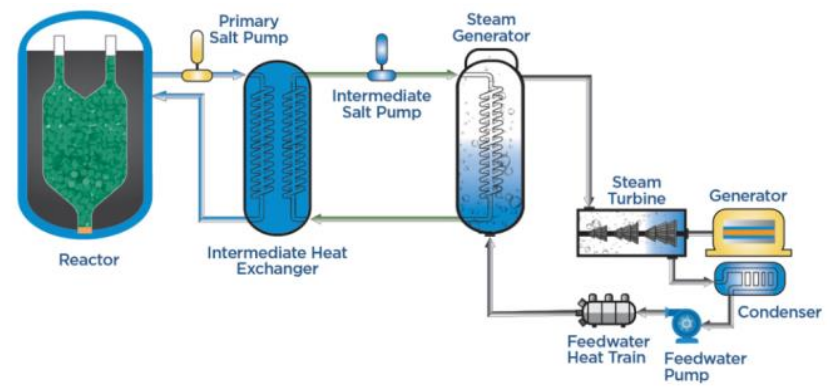

Fig. 3. Major components of the Kairos Power FHR power plant.

The Kairos Power FHR of Fig. 3 has fluoride primary coolant salt at $650{ }^{\circ} \mathrm{C}$ and nitrate salt in the intermediate coolant loop to isolate the steam generator from the primary coolant. The steam system generates $140 \mathrm{MWe}$ at $45 \%$ efficiency. The $3-\mathrm{cm}$ diameter graphite fuel pebbles containing thousands of tiny ceramic fuel kernels can retain fission products at very high temperatures. The buoyant pebbles float very slowly upward through the core in the coolant, which facilitates online inspection and refueling. The Kairos Power FHR uses proven HTGR fuel, 316 stainless steel structure, low pressure coolant, and passive decay heat cooling systems, so it could be developed quickly to generate affordable electricity.

\section{LIQUID FUEL THERMAL REACTOR}

The Integral Molten Salt Reactor (IMSR) of Terrestrial Energy has four coolant loops:

(1) The primary loop contains a fluoride salt with dissolved $\mathrm{UF}_{4}$ fuel, plus the fission products and actinides generated there. The salt may avoid $\mathrm{Li}$ and $\mathrm{Be}$, in order to minimize tritium generation. Fuel salt flows downward through the graphite moderator, and upward through six primary heat exchangers and pumps enclosed in the "integral" core, surrounded by a guard vessel and silo, Fig. 4. 


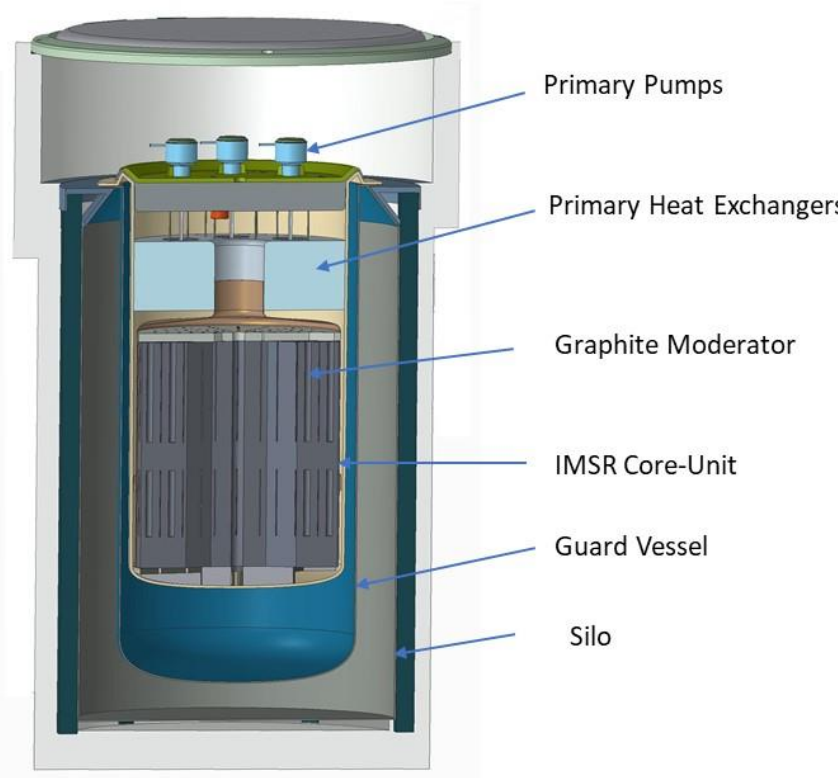

Fig. 4. IMSR400 guard vessel (blue) in silo with $R=1.7 \mathrm{~m}$.

(2) The secondary loop contains the same coolant salt, but no actinides or fission products. It carries high temperature heat and isolates the environment from the radioactive core.

(3) The tertiary loop uses a nitrate salt with lower melting temperature, to prevent salt freezing in the steam generator

(4) The Rankine cycle superheated steam loop generates electricity at $46-48 \%$ efficiency.

The IMSR400's low power density facilitates a graphite lifetime over 7 years. The three salt loops operate at low pressure, so thick pressure vessels are not needed. The first core burns for 7 years, then the companion core operates, while the first core cools. After the first core cools its silo is removed and stored nearby. A fresh core silo is installed in its place, ready to take over when the companion core has operated for 7 years. ${ }^{\text {ii }}$

There is no mechanical pressure or chemical energy release to mobilize radioactivity. Radiation and air convection remove core decay heat through the guard vessel and silo without human intervention, pumps, electricity, or water addition. This system could be deployed soon, because it does not require new technology development. Thermal reactors can have excellent safety features and satisfactory core life; but they would probably have lower power densities $(\sim 15$ $\left.\mathrm{MWt} / \mathrm{m}^{3}\right)$ than fast reactors $\left(\sim 300 \mathrm{MWt} / \mathrm{m}^{3}\right)$.

\section{LIQUID FUEL FAST REACTOR}

The European 3000 MWt Molten Salt Fast Reactor (MSFR)

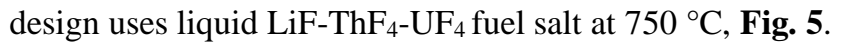

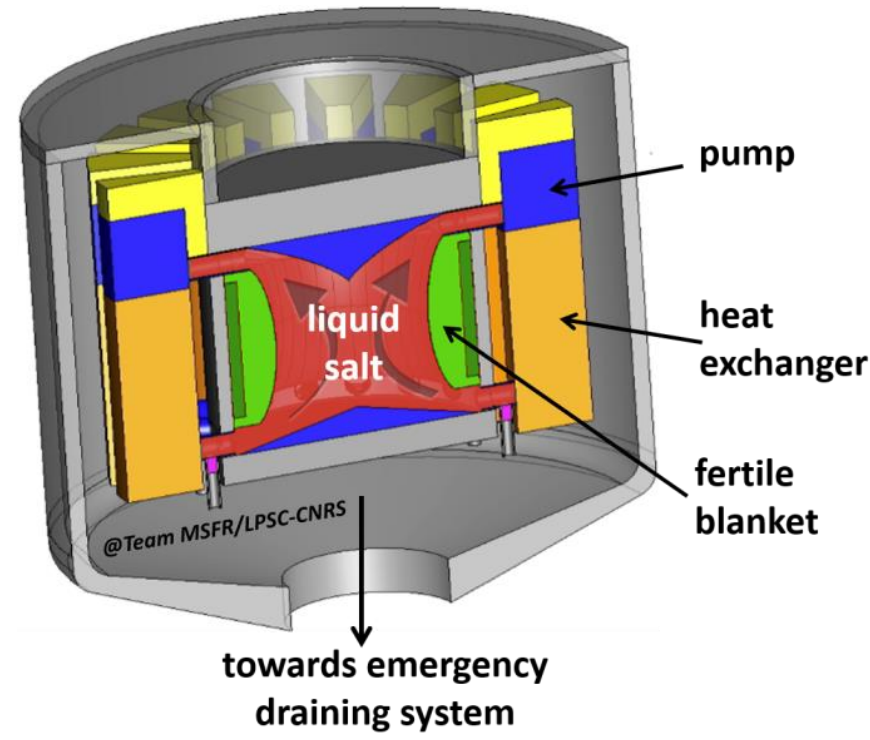

$\mathrm{S}$

Fig. 5. MSFR vessel with 16 heat exchanger loops. Core Diameter $=$ Height $=2.25 \mathrm{~m}$.

The fuel salt flows freely upward through the central part of the core without any solid moderator. The 16 return loops around the core contain pumps and heat exchangers. He bubbles are injected at the fuel inlets and separated from the liquid at the core outlet carrying volatile fission products. Half of the fuel salt volume is in the core and half is in the external circuit, and the fuel salt runs through the total cycle in $3.9 \mathrm{~s}$. TerraPower and Elysium Industries are also developing liquid fuel fast reactors. ${ }^{\text {iii }}$

Intermediate between solid fuel reactors and liquid fuel reactors is a combination called "Stable Salt Reactor".

\section{STABLE SALT REACTOR (SSR)}

The SSR is a fast spectrum MSR similar to sodium-cooled fast reactors. Instead of solid fuel rods the SSR design uses metal tubes of liquid fuel salt (red) with vented gas plenums at the tops, surrounded by a pool of clean chloride coolant salt (blue), Fig. 6. 


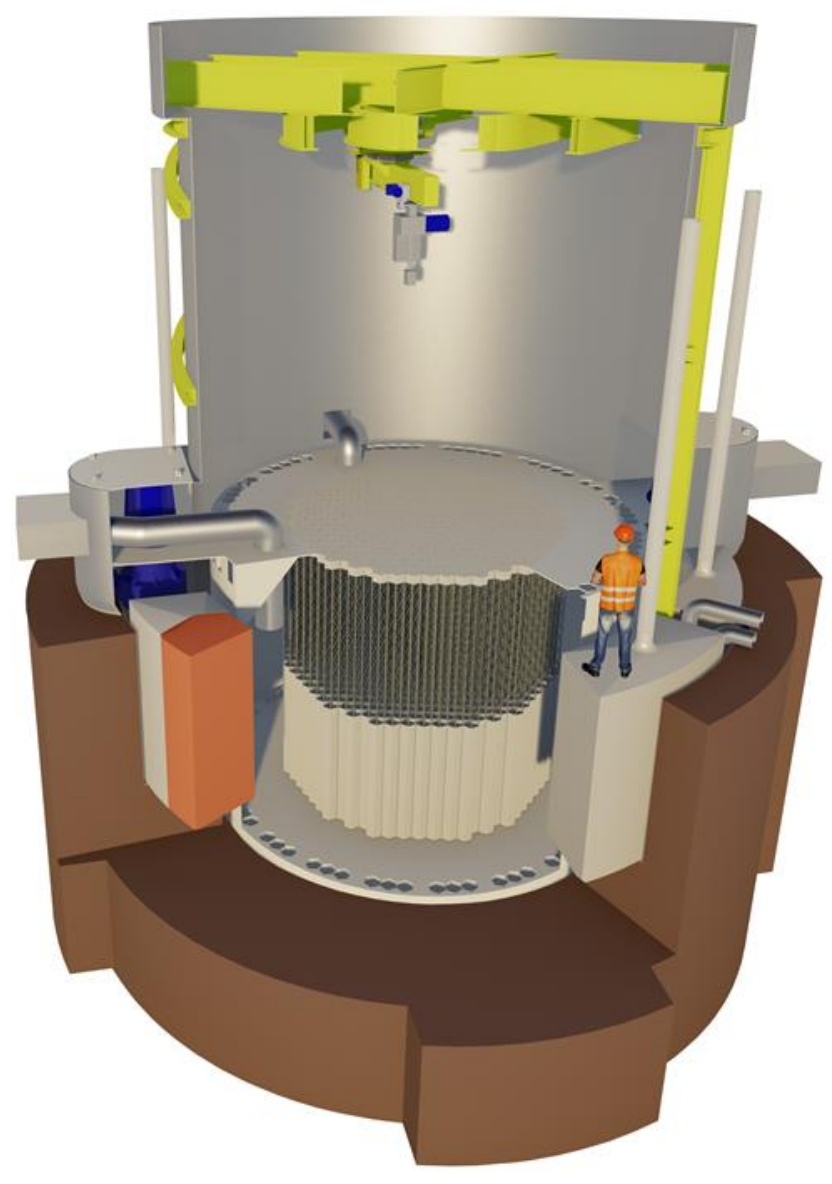

Fig. 6. Stable Salt Reactor design (Moltex).

The slow movement of liquid salt in each tube results in a uniform composition of the fuel salt. The fuel salt has no pellet-clad interactions or high-pressures from fission gas buildup. The primary coolant salt is "clean" (free of fission products and actinides), and redox potential control can minimize corrosion.

\section{LOAD FOLLOWING}

Solar and wind power require affordable energy storage or backup power sources that can be ramped up and down to meet the fluctuating demand. Natural gas turbines are good at load following, but emit greenhouse gases. Since MSRs can provide heat at high average temperature $(\sim 650 \mathrm{C})$ they can use hot air turbines that generate electricity at high efficiency, and heat can be stored in fire bricks. The bricks can be heated electrically when power is cheap and can supply heat when power is expensive. Even higher temperatures (> 1000 C) could be achieved with a topping cycle heated by electricity, hydrogen, or natural gas. Such storage is less feasible in reactors with lower average temperatures, such as gas-cooled, liquid metal-cooled, and water-cooled reactors. The MSR plant power can be varied rapidly (> $24 \mathrm{MW} /$ minute) over a wide power range at prices competitive with natural gas fired plants. ${ }^{\text {iv }}$

\section{REACTOR DESIGN PROJECTS}

Many MSR concepts are at various stages of preconceptual and conceptual design. Terrapower, is developing a chloride-salt MSR and is building dozens of Microloops (small natural circulation flow loops) to study salt properties and an Integral Effects Test (2020), to be followed by Test Reactor operations in 2025.

Kairos Power, with over 80 people, has opened major laboratories for development of the FHR with test loops at ORNL. Thorcon could manufacture many reactors at a shipyard and barge the components to sites for rapid assembly, with low cost of electricity and high rate of deployment. Other North American companies include Terrestrial Energy (described above), Flibe Energy, and Elysium Industries.

Groups in France, UK, Denmark, Germany, Russia, India, Japan, Korea, China, and others are also developing MSR technology and designs. ${ }^{\mathrm{v}}$ Europe has a large multinational group developing the Molten Salt Fast Reactor (described above).

The Shanghai Institute of Applied Physics has over 700 people working on solid fuel and liquid fuel MSRs, and several other Chinese laboratories are collaborating on component and salt development. ${ }^{\mathrm{vi}}$

MSR developers have an opportunity to create common international regulatory standards, which could facilitate faster and cheaper deployment of MSR reactors, if governments requested coordination by the IAEA.

\section{MSR DEVELOPENT PROBLEMS}

Although conceptual design studies emphasize the potential advantages of MSRs, many problems could delay progress:

- Remote maintenance in a hot, radioactive environment.

- Reliable heat exchangers for high temperature molten salt, such as molten salt to air heaters, steam generators, and salt-to-salt heat exchangers that prevent freezing, reduce fuel salt volume, and accommodate noble metal plate-out or clogging.

- Structural materials may be degraded by radiation damage, chemical corrosion, and creep at high temperatures. Better materials for reactor vessel and piping are desirable, such as non-nickel materials to minimize helium generation. If better materials were not developed, then early MSRs would need to limit the operational parameters to fit existing materials. ASME standards and irradiation qualification standards are needed.

- Reliable pumps and valves.

- Tritium control by choice of salts, intermediate coolant loops, tritium barriers, and removal systems. 
- Inexpensive isotope separation methods would be desirable to minimize tritium generation from ${ }^{6} \mathrm{Li}$ and ${ }^{36} \mathrm{Cl}$ generation from ${ }^{35} \mathrm{Cl}$.

- MSRs are not fully developed, and regulators lack MSR experience, so commercial licensing in the USA may be slow.

- Safeguards for nonproliferation of nuclear weapons must be thorough. Discussion of safeguards issues is beyond the scope of this article. The IAEA has many publications and experts who can help achieve safeguards by design.

- Liquid fuel flowing out of the reactor continues to emit delayed neutrons in the surrounding pipes and valves, which make the plumbing radioactive, so remote maintenance is required.

- For liquid fuel reactors, chemical systems to separate heavy metals, noble metals, volatile elements, and tritium in a highly radioactive environment with remote handling are the most difficult challenge. Technologies for salt processing were partly developed at ORNL in the 1960s. Now major advances in technologies are bringing new performance and cost advantages. This is an area of rapid change where it is unclear what the preferred salt processing options will be. ${ }^{\text {vii }}$

\section{CONCLUSION}

If the difficult MSR development issues could be resolved, then MSRs might achieve

- passive safety without auxiliary safety systems, aided by the absence of water in the core

- carbon-free electricity generation with good loadfollowing to compensate for fluctuations of solar and wind power

${ }^{\mathrm{i}}$ ROBERT HARGRAVES, Thorium Energy -- Cheaper than Coal, Robert Hargraves, Hanover, New Hampshire, 2012.

ii SIMON IRISH and DAVID LEBLANC, "The Integral Molten Salt Reactor”, Nuclear News 57 (12), December 2014, p. 54-58.

iii E. MERLE-LUCOTTE, M. ALLIBERT, M. BROVCHENKO, D. HEUER, V. GHETTA, A. LAUREAU, P. RUBIOLO, Introduction to the Physics of Thorium Molten Salt Fast Reactor (MSFR) Concept, in J.-P. Revol et al. (Editors), Thorium Energy for the World, DOI 10.1007/978-3319-26542-1_34

iv CHARLES FORSBERG \& PER F. PETERSON (2016) Basis for Fluoride Salt-Cooled High-Temperature Reactors with Nuclear Air-Brayton Combined Cycles and Firebrick Resistance-Heated Energy Storage, Nuclear Technology, 196:1, 13-33, DOI: 10.13182/NT16-28. C. W. FORSBERG, N. SEPULVEDA and K. DAWSON, "Commercialization
- efficient utilization of thorium and uranium energy with fewer waste products

- incineration of some actinides from used LWR fuels, reducing the need for long-term high-level waste storage

- lower power costs than water-cooled reactors and coal. Governments and industry should support a broad spectrum of concepts, until one or two prototype reactors turn out to have superior reliability, cost, and environmental benefits. Construction of test reactors is needed to demonstrate the technology, in addition to more paper studies. Based on manpower and resources devoted to MSR development, China is the world leader.

We envision a world where most countries have affordable molten salt reactors burning thorium, uranium, and spent fuel actinides, producing electricity, hydrogen, desalinated water, and other process heat applications, with no serious accidents.

\section{ACKNOWLEGMENT}

The author is grateful to the following for helpful comments: Leslie Dewan, Charles Forsberg, Robert Hargraves, Lars Jorgensen, John Kutsch, David LeBlanc, Ralph Moir, Imre Pazsit, Ed Pheil, Ian Scott, Darryl Siemer, and Ritsuo Yoshioka.

\section{REFERENCES}

Basis for Fluoride-salt-cooled High-Temperature Reactors (FHRs): Base-load Reactor with Heat Storage for Variable Electricity and High-Temperature Heat to Industry", MITANP-TR-178, August 2018.

v THOMAS J. DOLAN, Molten Salt Reactors and Thorium Energy (Elsevier, 2017)

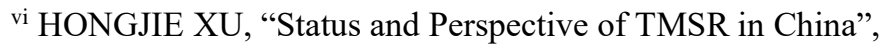
Presentation at PSI, Switzerland, 2017-01-24. Accessed

2019.04.14 at https://www.gen-

4.org/gif/upload/docs/application/pdf/201705/03_hongjie_xu_china.pdf

vii BRIAN J. RILEY, JOANNA MCFARLANE, GUILLERMO D. DELCUL, JOHN D. VIENNA, CRISTIAN I. CONTESCU, CHARLES W. FORSBERG, Molten salt reactor waste and effluent management strategies: A review, Nuclear Engineering and Design 345 (2019) 94-99. 
